\title{
Specific duodenal and faecal bacterial groups associated with paediatric coeliac disease
}

Maria Carmen Collado*, Ester Donat ${ }^{\dagger}$, Carmen Ribes-Koninckx ${ }^{\dagger}$, Miguel Calabuig ${ }^{\ddagger}$ and Yolanda Sanz $^{* 1}$

*Microbial Ecophysiology and Nutrition Group. Instituto de Agroquímica y Tecnología de Alimentos (CSIC), PO Box 73, 46100 Burjassot, Valencia, Spain.

${ }^{\dagger}$ Hospital Universitario La Fe, Avenida Campanar 21, 40009 Valencia, Spain.

${ }^{\ddagger}$ Hospital General Universitario, Avenida Tres Cruces s/n 46014 Valencia, Spain.

${ }^{1}$ Address correspondence and reprint requests to:

Dr. Yolanda Sanz

Instituto de Agroquímica y Tecnología de Alimentos (CSIC),

PO Box 73, 46100 Burjassot, Valencia, Spain.

Tel: +34 963900022 and Fax: +34 963636301.

E-mail: yolsanz@iata.csic.es

“The Corresponding Author has the right to grant on behalf of all authors and does grant on behalf of all authors, an exclusive licence (on non-exclusive for government employees) on a worldwide basis to the BMJ Publishing Group Ltd and its Licensees to permit this article to be published in Journal of Clinical Pathology editions and any other BMJPGL products to exploit all subsidiary rights”.

Running Title: Gut bacteria associated with coeliac disease

Key words: coeliac disease, gut microbiota, faeces, duodenum, qPCR

Word count: 2483 
Aims: To identify specific gut bacteria associated with coeliac disease (CD) at the diagnosis and after treatment with a gluten-free diet (GFD) in paediatric population.

Methods: 30 and 18 faecal samples from untreated and treated CD patients and 25 and 8 biopsy samples from untreated and treated CD patients, respectively, were analyzed. In addition, 30 faecal and 8 biopsy samples from control children were evaluated for comparative purposes. Gut bacterial groups were quantified by real-time PCR.

Results: Bacteroides and C. leptum groups were more abundant in faeces and biopsies of CD patients than in controls regardless the stage of the disease. E. coli and Staphylococcus counts were also higher in faeces and biopsies of non-treated CD patients than in those of controls but their levels were normalized after treatment with a GFD. Bifidobacterium levels were lower in faeces of both CD patients as well as in biopsies of untreated CD patients compared to controls. Similar bacterial groups were related to $\mathrm{CD}$ in biopsies and faeces, indicating that faecal microbiota partly reflects that of the small intestine in CD patients, and could constitute a convenient biological index of this disorder.

Conclusions: Duodenal and faecal microbiota is unbalanced in children with untreated CD and only partially restored after long-term treatment with a GFD, constituting a novel factor linked to this disorder.

Abbreviations: CD, coeliac disease; GFD, gluten-free diet; IBD, IBD. 


\section{INTRODUCTION}

Coeliac disease (CD) is a chronic inflammatory disorder of the small intestine characterized by a permanent intolerance to dietary gluten. This disease can manifest at any age with a variety of clinical features, but typical cases often presents in early childhood. [1] In the patients, gluten peptides elicit a Th1-type inflammatory immune response that causes intestinal villous atrophy, crypt hyperplasia and infiltration of intraepithelial lymphocytes. The ingestion of gluten is responsible for the signs and symptoms of $C D$, and its removal from the diet is currently the only available treatment. Moreover, other factors such as imbalances in the intestinal microbiota have been suggested to be associated with this disorder. [2-4] Infections could be involved in CD pathogenesis by both impairing mucosal barrier function and favouring the access of dietary gluten to sub-epithelial lymphoid tissue, and promoting a defensive Th1-mediated immune response with production of pro-inflammatory cytokines. [5] So far, differences in the microbiota composition and related metabolites between CD patients and healthy controls have been reported mainly in faeces, [3, 6, 7] whereas less information is available on the mucosaassociated microbiota.[2, 4] A rod-shape bacterium was previously found in most biopsy specimens of adult CD patients but it was not identified. [2] More recently, specific studies have been carried out to characterize the duodenal microbiota of CD patients [4]; however, comparisons between mucosal and faecal microbiota in patients with active disease and treated with a gluten-free diet (GFD) are not available so as to define which are the bacterial groups relevant to the disease. In fact, other reports have described differences between the microbiota composition of mucosal and faecal samples in healthy subjects [8] as well as in allergy and inflammatory bowel disease (IBD) patients. $[9,10]$

The objective of this study was to assess in a comparative manner the composition of the duodenal and faecal microbiota of CD patients (untreated and treated with a GFD) and healthy age-matched controls, as well as to establish possible relations between biopsy and faecal associated bacteria and this disorder by the use of real-time PCR.

\section{PATIENTS and METHODS}

\section{Subjects}

Three groups of children were included in this study: (1) untreated CD patients on a normal gluten-containing diet (56.4-60.6 months old); (2) treated CD patients with a GFD for at least 2 years (63.5-57.8 months old); and (3) control children without gluten intolerance (45.0-49.2 months old). The following faecal samples and duodenal biopsy specimens were analysed: 30 faecal and 25 biopsy samples from untreated CD patients; 18 faecal and 8 biopsy samples from treated CD patients and 30 faecal and 8 biopsy samples from control children. None of the children included in the study was treated with antibiotics for at least 1 month before the sampling time.

\section{Sample preparation and DNA extraction}

Faecal and biopsy samples were frozen immediately at $-20^{\circ} \mathrm{C}$ and kept until processing. Duodenal biopsy specimens were obtained by upper intestinal capsule or endoscopy. Faeces (1g) and duodenal biopsy samples (10-15 mg) were diluted 1: 10 (w/v) in PBS (pH 7.2), homogenized and used for DNA extraction. DNA from pure cultures of reference bacterial strains and faecal and biopsy samples were extracted using the QIAamp DNA stool Mini kit (Qiagen, Hilden, Germany) following the manufacturer's instructions.

\section{Quantitative real-time PCR (qPCR) analysis}

Quantitative real time PCR was used to characterize the gut microbiota by use of specific primers targeting different bacterial groups and the SYBR ${ }^{\circledR}$ Green PCR Master Mix (SuperArray Bioscience Corporation, USA), as previously described (Table 1). PCR amplification and detection were performed with an ABI PRISM 7000-PCR sequence detection system (Applied 
Biosystems, UK). Bacterial concentration from each sample was calculated by comparing the Ct values obtained from standard curves that were created by using serial 10 -fold dilution of pure cultures DNA corresponding to $10^{2}$ to $10^{9}$ cells. The following strains were used as references: Bifidobacterium longum subsp. longum CECT 4503, Bacteroides fragilis DSMZ 2451, Clostridium coccoides DSMZ 933, C. leptum DSMZ 935, Staphylococcus aureus CECT 86, Lactobacillus casei ATCC 393, E. coli CECT 45 and Akkermansia muciniphila strain Muc ${ }^{\mathrm{T}}$ (ATCC BAA-835 ${ }^{\mathrm{T}}$ ).

Table 1. Oligonucleotide primers used in this study.

\begin{tabular}{|c|c|c|c|}
\hline Target bacterial group/species & Sequence $\left(5^{\prime}-33^{\prime}\right)$ & Annealing Tmp $\left({ }^{\circ} \mathrm{C}\right)$ & References \\
\hline Total counts & $\begin{array}{l}\text { TGGCTCAGGACGAACGCTGGCGGC } \\
\text { CCTACTGCTGCCTCCCGTAGGAGT }\end{array}$ & 56 & [21] \\
\hline Bifidobacterium group & $\begin{array}{l}\text { CTCCTGGAAACGGGTGG } \\
\text { GGTGTTCTTCCCGATATCTACA }\end{array}$ & 55 & [22] \\
\hline Bacteroides group & $\begin{array}{l}\text { ATA GCC TTT CGA AAG RAA GAT } \\
\text { CCA GTA TCA ACT GCA ATT TTA }\end{array}$ & 50 & [22] \\
\hline Clostridium coccoides group & $\begin{array}{l}\text { AAA TGA CGG TAC CTG ACT AA } \\
\text { CTT TGA GTT TCA TTC TTG CGA A }\end{array}$ & 50 & {$[22]$} \\
\hline Clostridium leptum group & $\begin{array}{l}\text { GCA CAA GCA GTG GAG T } \\
\text { CTT CCT CCG TTT TGT CAA }\end{array}$ & 50 & {$[22]$} \\
\hline E. coli & $\begin{array}{l}\text { GTTAATACCTTTGCTCATTGA } \\
\text { ACCAGGGTATCTAATCCTGTT }\end{array}$ & 62 & [23] \\
\hline Staphylococcus group & $\begin{array}{c}\text { GCGATTGATGGTGATACGGTT } \\
\text { AGCCAAGCCTTGACGAACTAAAGC }\end{array}$ & 61 & [24] \\
\hline Lactobacillus group & $\begin{array}{l}\text { GGAAACAG(A/G)TGCTAATACCG } \\
\text { CACCGCTACACATGGAG }\end{array}$ & 61 & {$[23]$} \\
\hline Akkermansia muciniphila & $\begin{array}{l}\text { CAGCACGTGAAGGTGGGGAC } \\
\text { CCTTGCGGTTGGCTTCAGAT }\end{array}$ & 60 & [25] \\
\hline
\end{tabular}

\section{Statistical analyses}

Statistical analyses were done using the SPSS 11.0 software (SPSS Inc, Chicago, IL, USA). Due to non-normal distribution, microbial data are expressed as medians with interquartile ranges (IQR) and the differences between two groups of samples were determined by applying the Mann-Whitney $U$ test. Correlations between variables were determined by applying the Spearman rank correlation coefficient. Differences in prevalence of bacterial groups were established by applying the chi-square test. A p $<0.050$ was considered statistically significant.

\section{RESULTS}

\section{Subjects}

Clinical characteristics of the different groups of CD children included in the study are shown in Table 2. 
Table 2. Clinical characteristics of the children included in the study.

\begin{tabular}{|c|c|c|c|}
\hline Characteristics & Untreated CD & Treated CD & Healthy \\
\hline Number of patients & 30 & 18 & 30 \\
\hline Age (average months and SD) & $56.4(38.5)$ & $65.2(37.75)$ & $45.0(33.5)$ \\
\hline \multicolumn{4}{|l|}{ Gender } \\
\hline - male & $12 / 30[40.0 \%]$ & $8 / 18[44.4 \%]$ & $13 / 30[43.3 \%]$ \\
\hline - female & $18 / 30[60.0 \%]$ & $10 / 18[55.6 \%]$ & $17 / 30[56.7 \%]$ \\
\hline \multicolumn{4}{|l|}{ Clinical } \\
\hline - Asymptomatic & - & - & - \\
\hline - Abdominal & $2 / 30[6.6 \%]$ & - & - \\
\hline - Diarrhoea & $28 / 30[93.4 \%]$ & $2 / 18[11.1 \%]$ & - \\
\hline - Weight loss & $9 / 30[30.0 \%]$ & - & - \\
\hline - Anaemia & $14 / 30[46.6 \%]$ & $8 / 18[44.4 \%]$ & - \\
\hline \multicolumn{4}{|l|}{ Biochemical } \\
\hline - Asymptomatic & $4 / 30[13.3 \%]$ & $18 / 18[100.0 \%]$ & - \\
\hline - Iron deficiency & $10 / 30[33.3 \%]$ & - & - \\
\hline \multicolumn{4}{|l|}{ Serology } \\
\hline AGA = anti-gliadin antibodies & $\mathrm{AGA}+[100.0 \%]$ & $\mathrm{AGA}-[100.0 \%]$ & AGA - $[100.0 \%]$ \\
\hline $\mathrm{t}-\mathrm{TG}=$ anti-transglutaminase antibodies & $\mathrm{t}-\mathrm{TG}+[100.0 \%]$ & $\mathrm{t}-\mathrm{TG}-[100.0 \%]$ & $\mathrm{t}-\mathrm{TG}-[0.0 \%]$ \\
\hline HLA genetic typing & $\mathrm{DQ} 2+[100.0 \%]$ & $\mathrm{DQ} 2+[100.0 \%]$ & - \\
\hline \multirow{2}{*}{ Duodenal Biopsy ${ }^{2}$} & M0-1 $[0.0 \%]$ & M0-1 $[100.0 \%]$ & \multirow{2}{*}{ Mo $[100.0 \%]$} \\
\hline & M3 $[100.0 \%]$ & M3 $[0.0 \%]$ & \\
\hline
\end{tabular}

\footnotetext{
"Modified Marsh Classification of CD. [11] M0: Nomal nucosa; CD highly unlikely. M0-1: (Infiltrative lesion): Seen in patients on a gluten-free diet (suggesting minimal amounts of gliadin are being ingested); patients with dermatitis herpetifomis (DH); and family members of patients with CD. M2 (Hyperplastic type): Very rare; seen occasionally in DH. M3: $>40$ Intraepithelial Lymphocytes per 100 Enterocytes, Crypts increased and villi with atrophy (partial or complete villous atrophy).
}

Untreated CD patients were on a normal gluten-containing diet, showed clinical symptoms of the disease, positive coeliac serology markers (anti-gliadin antibodies and anti-transglutaminase antibodies) and signs of severe enteropathy by duodenal biopsy examination classified as type 3 according to Marsh classification of CD. [11] Treated CD patients were on a gluten-free diet for at least 2 years, showed negative coeliac serology markers and normal mucosa or infiltrative lesion classified as type 0-1 according to Marsh classification.

\section{Faecal microbiota composition in CD patients and control children}

The prevalence and bacterial counts of faecal samples from the three groups of children under study assessed by qPCR is shown in Tables 3 and 4 . The prevalence of $E$. coli was significantly higher in untreated $(\mathrm{p}=0.012)$ and treated CD patients $(\mathrm{p}=0.031)$ than in control children (Table $3)$. Staphylococcus was less prevalent in controls than in untreated CD patients $(p=0.026)$ and treated CD patients $(\mathrm{p}=0.085)$. 
Table 3. Prevalence of bacterial groups in faeces and duodenal biopsies of children

\begin{tabular}{|c|c|c|c|c|c|c|}
\hline \multirow[b]{2}{*}{ Bacterial groups } & \multicolumn{3}{|c|}{ Prevalence $^{n}$ in faecal samples } & \multicolumn{3}{|c|}{ p-value Chi-square test } \\
\hline & $\begin{array}{c}\text { Untreated CD } \\
(n=30)\end{array}$ & $\begin{array}{c}\text { Treated CD } \\
(n=18)\end{array}$ & $\begin{array}{l}\text { Control } \\
(n=30)\end{array}$ & $\begin{array}{l}\text { Untreated- } \\
\text { treated CD }\end{array}$ & $\begin{array}{l}\text { Untreated CD- } \\
\text { control }\end{array}$ & $\begin{array}{c}\text { Treated CD- } \\
\text { control }\end{array}$ \\
\hline Total counts & $30 / 30[100.0 \%]$ & $18 / 18[100.0 \%]$ & $30 / 30[100.0 \%]$ & - & - & - \\
\hline Bifidobacterium & $30 / 30[100.0 \%]$ & $18 / 18[100.0 \%]$ & $30 / 30[100.0 \%]$ & - & - & - \\
\hline Bacteroides & $30 / 30[100.0 \%]$ & $18 / 18[100.0 \%]$ & $30 / 30[100.0 \%]$ & - & - & - \\
\hline Staphylococcus & $30 / 30[100.0 \%]$ & $18 / 18[100.0 \%]$ & $25 / 30[83.3 \%]$ & - & $0.026^{*}$ & 0.083 \\
\hline C.coccoides & $30 / 30[100.0 \%]$ & $18 / 18[100.0 \%]$ & $30 / 30[100.0 \%]$ & - & - & - \\
\hline C. leptum & $29 / 30[96.6 \%]$ & $18 / 18[100.0 \%]$ & $30 / 30[100.0 \%]$ & - & - & - \\
\hline Lactobacillus & $30 / 30[100.0 \%]$ & $18 / 18[100.0 \%]$ & $30 / 30[100.0 \%]$ & - & - & - \\
\hline E. coli & $25 / 30[83.3 \%]$ & $15 / 18[83.3 \%]$ & $15 / 30[50.0 \%]$ & 0.645 & $0.012 *$ & $0.031 *$ \\
\hline \multirow[t]{2}{*}{ A. muciniphila } & $27 / 30[90.0 \%]$ & $15 / 18[83.3 \%]$ & $25 / 30[83.3 \%]$ & 0.658 & 0.480 & 0.980 \\
\hline & \multicolumn{3}{|c|}{ Prevalence in biopsy samples } & \multicolumn{3}{|c|}{ p-value Chi-square test } \\
\hline Bacterial groups & $\begin{array}{l}\text { Untreated CD } \\
(\mathrm{n}=25)\end{array}$ & $\begin{array}{c}\text { Treated CD } \\
(\mathrm{n}=8)\end{array}$ & $\begin{array}{l}\text { Control } \\
(\mathrm{n}=8)\end{array}$ & $\begin{array}{l}\text { Untreated- } \\
\text { treated CD }\end{array}$ & $\begin{array}{l}\text { Untreated CD- } \\
\text { control }\end{array}$ & $\begin{array}{l}\text { Treated CD- } \\
\text { control }\end{array}$ \\
\hline Total counts & $25 / 25[100.0 \%]$ & $8 / 8[100.0 \%]$ & $8 / 8[100.0 \%]$ & - & - & - \\
\hline Bifidobacterium & $25 / 25[100.0 \%]$ & $8 / 8[100.0 \%]$ & $8 / 8[100.0 \%]$ & - & - & - \\
\hline Bacteroides & $25 / 25[100.0 \%]$ & $8 / 8[100.0 \%]$ & $8 / 8[100.0 \%]$ & - & - & - \\
\hline Staphylococcus & $13 / 25[52.0 \%]$ & $3 / 8[37.5 \%]$ & $2 / 8[25.0 \%]$ & 0.688 & 0.241 & 0.641 \\
\hline C.coccoides & $18 / 25[72.0 \%]$ & $4 / 8[50.0 \%]$ & $8 / 8[100.0 \%]$ & 0.391 & 0.154 & $0.038^{*}$ \\
\hline C. leptum & $11 / 25[44.0 \%]$ & $4 / 8[50.0 \%]$ & $4 / 8[50.0 \%]$ & 0.980 & 0.766 & 0.980 \\
\hline Lactobacillus & $25 / 25[100.0 \%]$ & $4 / 8[50.0 \%]$ & $8 / 8[100.0 \%]$ & $0.002^{*}$ & - & $0.038^{*}$ \\
\hline E. coli & $10 / 25[40.0 \%]$ & $2 / 8[25.0 \%]$ & $2 / 8[25.0 \%]$ & 0.677 & 0.677 & 0.715 \\
\hline A. muciniphila & $13 / 25[48.0 \%]$ & $0 / 8[0.0 \%]$ & $2 / 8[25.0 \%]$ & $0.011^{*}$ & 0.241 & 0.466 \\
\hline
\end{tabular}

${ }^{2}$ Prevalence $(\mathrm{Pr})$ reflects the number of positive amplifications from total samples analysed by PCR ( $\mathrm{n}=$ number of samples analysed)

* Statistical differences were calculated by using Chi-square test $2 \times 2$. Significantly difference between groups was established at $P<0.050$

Total bacterial counts were significantly lower in control children than in untreated CD ( $\mathrm{p}=$ 0.009 ) and treated CD patients $(\mathrm{p}=0.039)$ (Table 4). Bacteroides and C. leptum groups were also present in significantly higher numbers in both untreated $(p=0.028$; and 0.012 , respectively) and treated CD patients ( $\mathrm{p}=0.015$, and $<0.001$, respectively) compared to controls (Table 4). E. coli counts were also higher in both untreated and treated CD patients than in controls although the differences were only significant between untreated CD patients and controls $(p=0.011)$.Total bacteria, Bacteroides, C. leptum and E. coli group counts were not significant different between untreated and treated CD patients ( $>>0.05)$. Staphylococcus levels were significantly higher in untreated CD patients than in treated CD patients $(p=0.007)$ and controls $(p=0.031)$. Bifidobacterium counts were significantly higher in control children than in untreated $(p=0.014)$ and treated CD patients $(\mathrm{p}=0.002)$. Lactobacillus group levels were significantly different only between treated CD patients and controls $(\mathrm{p}=0.035)$.

\section{Duodenal microbiota composition in CD patients and control children}

The prevalence and bacterial counts of duodenal biopsies and faeces from the three studied groups of children (untreated and treated CD patients and controls) is shown in Table 3 and 4 . The prevalence of $C$. coccoides group was higher in healthy controls than in untreated $(p=0.038)$ and treated CD patients ( $\mathrm{p}=0.154)$. Lactobacillus prevalence was significantly higher in untreated than treated CD patients $(\mathrm{p}=0.002)$ and it was also higher in controls than in treated CD patients $(\mathrm{p}=0.038)$. A. muciniphila prevalence was significantly higher $(\mathrm{p}=0.011)$ in untreated than in treated CD patients. 
Table 4. Bacterial group counts analyzed by $\mathrm{qPCR}$.

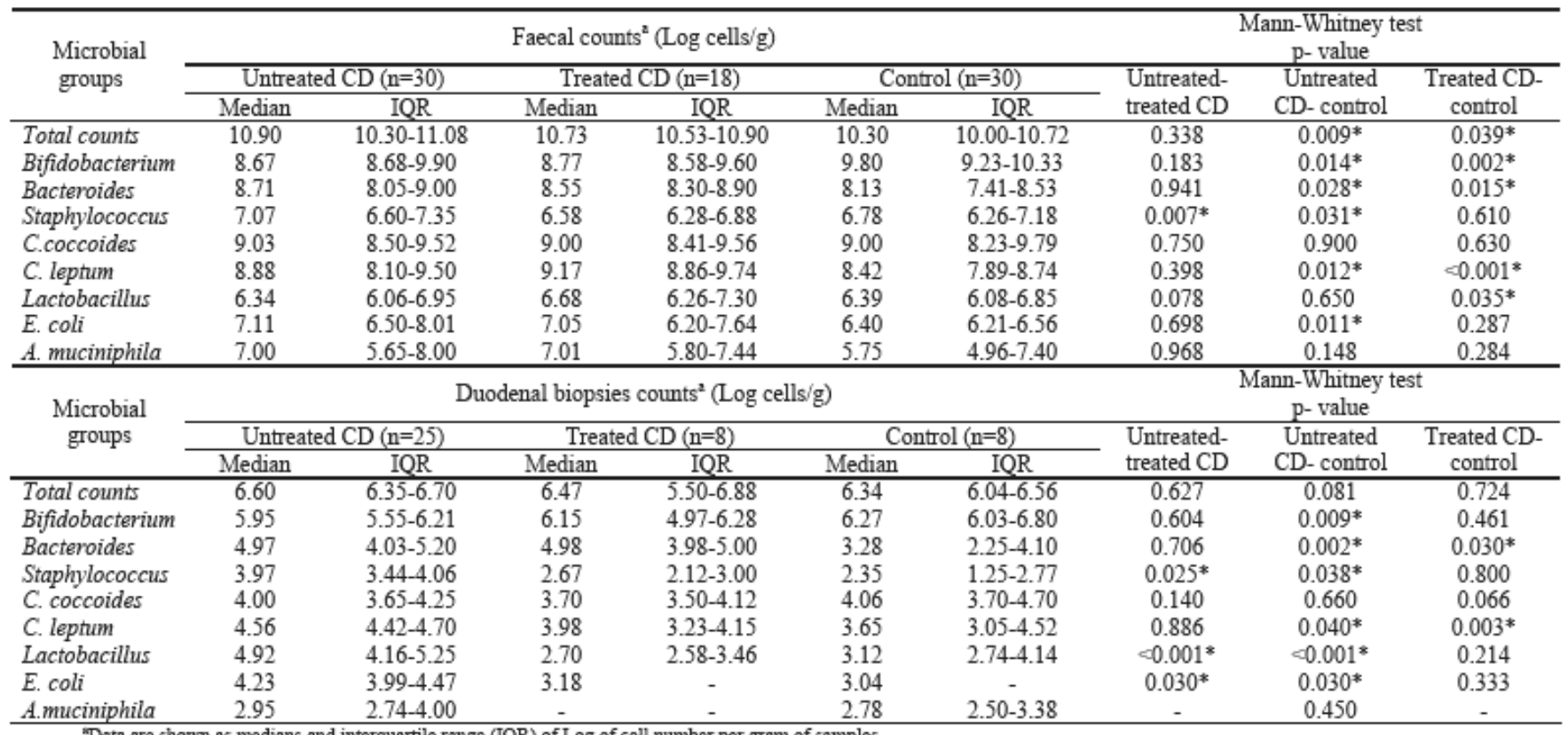

"Data are shown as medians and interquartile range (IQR) of Log of cell number per gram of samples

- Statistical differences were calculated using Mann-Whitney U-test. Significantly different at $p<0.05$

Untreated CD patients showed the highest total bacterial counts in biopsies, followed by treated CD patients and controls, although the differences were not significant (Table 4). Bacteroides and C. leptum groups were present in significantly higher numbers in both untreated $(p=0.002$ and $p=$ 0.040 , respectively) and treated $(\mathrm{p}=0.030$ and $\mathrm{p}=0.003$, respectively) CD patients than in controls. Staphylococcus and E. coli group were present in higher levels in untreated CD patients than in treated patients $(p=0.025$ and 0.030 , respectively) and controls $(p=0.038$ and 0.030 , respectively), whereas significant differences were not found between treated CD samples and control samples. Bifidobacterium counts were significantly higher in control children than in untreated CD patients $(\mathrm{p}=0.009)$ although no differences were found comparing controls with treated CD patients $(\mathrm{p}=0.461)$. Lactobacillus group levels were lower in treated CD patients $(\mathrm{p}<$ $0.001)$ and controls $(\mathrm{p}<0.001)$ than in untreated CD patients, whereas no differences were detected between controls and treated CD patients $(p=0.214)$.

\section{Relations between microbiota composition of biopsy and faecal samples}

The correlations found between bacterial counts of faeces and biopsies considering all samples are shown in Fig 1. In addition, correlations were detected between the faecal and biopsy levels of Bifidobacterium in untreated CD patients $(\mathrm{R}=0.86, \mathrm{p}<0.001)$, treated CD patients $(\mathrm{R}=0.67$, $\mathrm{p}<0.001)$ and controls $(\mathrm{R}=0.68, \mathrm{p}<0.001)$. Correlations were also detected between the faecal and biopsy levels of Bacteroides $(\mathrm{R}=0.86, \mathrm{p}<0.001)$, Staphylococcus $(\mathrm{R}=0.80, \mathrm{p}<0.001), C$. coccoides $(\mathrm{R}=0.83, \mathrm{p}<0.001)$, C. leptum $(\mathrm{R}=0.77, \mathrm{p}<0.001)$, Lactobacillus $(\mathrm{R}=0.83, \mathrm{p}<$ $0.001)$, E. coli $(\mathrm{R}=0.82, \mathrm{p}<0.001)$ and $A$. muciniphila $(\mathrm{R}=0.78, \mathrm{p}<0.001)$ in untreated $\mathrm{CD}$ patients. Similarly, correlations were detected for Bacteroides $(\mathrm{R}=0.71$ and $\mathrm{R}=0.68, \mathrm{p}<0.001)$, Staphylococcus $(\mathrm{R}=0.61, \mathrm{p}=0.004$ and $\mathrm{R}=0.44, \mathrm{p}=0.017)$, C. coccoides $(\mathrm{R}=0.71$ and $\mathrm{R}=0.68, \mathrm{p}$ $<0.001)$, C. leptum $(\mathrm{R}=0.67$ and $\mathrm{R}=0.85, \mathrm{p}=0.001)$, Lactobacillus $(\mathrm{R}=0.67, \mathrm{p}=0.001$ and $\mathrm{R}=0.69, \mathrm{p}<0.001$, respectively), $E$. coli $(\mathrm{R}=0.86, \mathrm{p}=0.05$ and $\mathrm{R}=0.66, \mathrm{p}=0.020)$ in treated $\mathrm{CD}$ patients and controls. A. muciniphila correlation was only detected in controls $(\mathrm{R}=0.51, \mathrm{p}$-value $=$ $0.003)$. 


\section{DISCUSSION}

This is the first comparative study on the relations between the faecal and duodenal mucosaassociated microbiota of CD patients, untreated and treated by a long-term GFD, providing new insights into the possible role of bacteria in CD pathogenesis at different stages of the disease.

Bacteroides and C. leptum groups were significantly more abundant in faeces and biopsies of both CD patients than in healthy controls, regardless the stage of the disease. Significantly increased levels of Bacteroides were also previously detected in faeces and biopsies of untreated CD patients compared to controls by in situ hybridization and flow cytometry techniques; [3, 4] moreover, significant differences have been found between treated and healthy controls in both faeces and biopsies in the present study, providing sounder links between Bacteroides and the disease. With a few exceptions, [10] increased levels of Bacteroides have also been detected in the gut microbiota of patients suffering from Crohn's disease, which is also characterized by Th1type polarized response. [12] In IBD patients the concentration of Bacteroides associated with the mucosa was shown to be higher and increased with the severity of the disease. [13] The obtained results are also in agreement with the microbial differences found between faecal samples from two population groups with high and low incidence of allergies and CD (Swedish and Estonian infants), characterized by increased levels of Bacteroides and Clostridium in the former population group. [14] C. leptum group has also been identified as the clostridia probably contributing to increases in total Clostridium levels previously detected in faeces of untreated CD patients compared with controls. [3] Information of the significance of this bacterial group in duodenal microbiota of CD patients has been newly reported here.

The prevalence of E. coli and Staphylococcus was significantly or almost significantly higher in faeces of both CD patients than in those of controls. In addition, E. coli and Staphylococcus counts were significantly higher in faeces and biopsies of non-treated CD patients than in those of controls but their levels were normalized after the treatment with a GFD in parallel to the remission of the mucosal lesion. Therefore, these two bacterial groups seemed to be associated with the active phase of the disease and their increases could be a secondary consequence of the inflammatory milieu trigger by gluten ingestion. In IBD patients numbers of $E$. coli associated with the mucosa were also increased. [15] In addition, an adherent invasive E. coli pathovar was identified in the mucosa of patients with Crohn's disease, which was able to replicate and induce tumour necrosis factor alpha (TNF- $\alpha$ ) production in macrophages. [16] Increased levels of Staphylococcus in duodenal biopsies of untreated CD patients compared with controls have been detected in agreement with a previous study of faeces collected only from untreated CD patients [3]

Increased levels of Staphylococcus and Enterobacteriaceae were also higher in allergy infants compared to healthy infants, suggesting a relationship between these bacterial groups and immune dysregulation. [17]

Bifidobacterium levels were significantly lower in faeces of both CD patients as well as in biopsies of untreated CD patients compared to control children. A similar trend was detected in biopsy and faecal sample of untreated CD patients and controls but the differences were not significant. [3, 4] These results suggest that either Bifidobacterium could protect against CD or inherent features of the CD intestine influence Bifidobacterium colonization. Bifidobacterium numbers in the mucosa of IBD patients were also reduced compared to controls. [18, 19] The same trend was reported for allergic infants compared to healthy infants, [17] constituting the basis for the proposed use of probiotic bacteria in the management of this disorder. [20]

Significant correlations were found between the main bacterial group counts detected in biopsies and faeces. In fact, similar bacterial groups were related to CD in biopsies and faeces, indicating that faecal microbiota partly reflects that of the small intestinal mucosa in CD patients, and could constitute a convenient biological marker of this disorder.

In summary, this study has demonstrated that both duodenal and faecal microbiota is unbalanced in untreated CD children and only partially restored after long-term adherence to a GFD. 
Therefore, specific components of the gut microbiota could be viewed as novel factors contributing to the disease and as possible faecal indexes of this disorder.

\section{ACKNOWLEDGEMENTS and FUNDINGS}

This work was supported by grants AGL-2005-05788-C02-01 and Consolider Fun-C-Food CSD2007-00063 from the Spanish Ministry of Science and Innovation. I3P-CSIC Postdoctoral Contract from the European Social Fund to M.C. Collado is fully acknowledged.

Akkermansia muciniphila strain $\mathrm{Muc}^{\mathrm{T}}$ (=ATCC BAA-835 ${ }^{\mathrm{T}}=\mathrm{CIP} 107961^{\mathrm{T}}$ ) was kindly provided by Molecular Microbial Ecology Group, Laboratory of Microbiology, Department of Agrotechnology and Food Sciences, Wageningen University, Wageningen, The Netherlands.

\section{COMPETING INTERESTS}

None of the authors has conflict of interests.

\section{ETHICS APPROVAL}

Ethics approval was obtained from the ethics committee of CSIC and the hospitals taking part in the study (Hospital Universitario La Fe and Hospital General Universitario, Valencia, Spain).

\section{FIGURE LEGEND}

Figure 1. Correlations between bacterial group counts of faeces and duodenal biopsies from untreated patients (dark grey box), non-treated patients (grey box) and controls (white box). Data represent the positive samples. The line in the box is the median (50\% percentile), with the lower line the lower $25 \%$ border (25\% percentile) and the upper line the $75 \%$ (75\% percentile) border. The end of the upper vertical line is the maximum data value, outliers not considered. The end of the lower vertical line is the lowest value, outliers not considered. The separate dots or asterisks indicate outliers. Correlations values included in the figure were done using all positive simples from faeces and duodenal biopsies. Significant correlations were established at $\mathrm{p}<0.05$. 


\section{REFERENCES}

1. Fasano A, Catassi C. Coeliac disease in children. Best Pract Res Clin Gastroenterol 2005; 19: 467-78.

2. Forsberg G, Fahlgren A, Horstedt $P$, et al. Presence of bacteria and innate immunity of intestinal epithelium in childhood coeliac disease. Am J Gastroenterol 2004; 99: 894-904.

3. Collado MC, Calabuig M, Sanz Y. Differences between the faecal microbiota of coeliac children and healthy controls. Curr Issues Intest Microbiol 2007; 8: 9-14.

4. Nadal I, Donat E, Ribes-Koninckx C, et al. Imbalance in the composition of the duodenal microbiota of children with coeliac disease. J Med Microbiol 2007; 56(12):1669-74.

5. Sanz Y, Sánchez E, De Palma, G, et al. Indigenous gut microbiota, probiotics, and coeliac disease. In: Overton LT \& Ewente MR, eds. Child Nutrition \& Physiology. New York, USA: Nova Science Publishers Inc.; 2008

6. Tjellstrom B, Stenhammar L, Hogberg L, et al. Gut microflora associated characteristics in children with coeliac disease. Am J Gastroenterol 2005; 100: 2784-8.

7. Sanz Y, Sánchez E, Marzotto M, et al. Differences in faecal bacterial communities in coeliac and healthy children as detected by PCR and denaturing gradient gel electrophoresis. FEMS Immunol Med Microbiol 2007; 51(3):562-8.

8. Wang M, Ahrne S, Jeppsson B, et al. Comparison of bacterial diversity along the human intestinal tract by direct cloning and sequencing of 16S rRNA genes. FEMS Microbiol Ecol 2005; 54: 219-231.

9. Ouwehand AC, Salminen S, Arvola T, et al. Microbiota composition of the intestinal mucosa: association with fecal microbiota? Microbiol Immunol 2004; 48(7):497-500.

10. Conte MP, Schippa S, Zamboni I, et al. Gut-associated bacterial microbiota in paediatric patients with IBD. Gut 2006; 55(12):1760-7.

11. Dickson BC, Strentker CJ, Chetty R. Coeliac disease: an update for pathologists. J Clin Pathol 2006; 59: 1008-1016

12. Sartor RB. Therapeutic manipulation of the enteric microflora in IBDs: antibiotics, probiotics, and prebiotics. Gastroenterology 2004; 126: 1620-33.

13. Swidsinski A, Ladhoff A, Pernthaler A, et al. Mucosal flora in IBD. Gastroenterology 2002; 122: 44-54.

14. Sepp E, Julge K, Vasar M, et al. Intestinal microflora of Estonian and Swedish infants. Acta Paediatr 1997; 86: 956-61.

15. Rhodes JM. The role of Escherichia coli in IBD. Gut 2007; 56(5):610-2.

16. Darfeuille-Michaud A, Boudeau J, Bulois P, et al. High prevalence of adherent-invasive Escherichia coli associated with ileal mucosa in Crohn's disease. Gastroenterology 2004; 127:412-421.

17. Björkstén B, Sepp E, Julge K, et al. Allergy development and the intestinal microflora during the first year of life. J Allergy Clin Immunol 2001; 108(4):516-20.

18. Macfarlane S, Furrie E, Kennedy A, et al. Mucosal bacteria in ulcerative colitis. $\mathrm{Br} \mathrm{J}$ Nutr 2005; 93: S67-S72.

19. Mylonaki M, Rayment NB, Rampton DS, et al. Molecular characterization of rectal mucosa-associated bacterial flora in IBD. Inflamm Bowel Dis 2005; 11: 481-7.

20. Salminen S, Isolauri, E. Intestinal colonization, microbiota and probiotics. J Pediatr 2006; 149: S115-S120.

21. Ward L, Brown J, Graham D. Two methods for the genetic differentiation of Lactococcus lactis and cremoris based on differences in the 16S rRNA gene sequence. FEMS Microbiol Lett 1998; 166: 15-21.

22. Matsuki T, Watanabe K, Fujimoto J, et al. Use of 16S rRNA gene-targeted groupspecific primers for real-time PCR analysis of predominant bacteria in human feces. Appl Environ Microbiol 2004; 70:7220-8. 
23. Malinen E, Rinttilä $\mathrm{T}$, Kajander $\mathrm{K}$, et al. Analysis of the fecal microbiota of irritable bowel syndrome patients and healthy controls with real-time PCR. Am J Gastroenterol 2005; 100(2):373-82.

24. Fang H, Hedin G. Rapid screening and identification of methicillin-resistant Staphylococcus aureus from clinical samples by selective-broth and real-time PCR assay. J Clin Microbiol 2003; 41(7):2894-2899.

25. Collado MC, M. Derrien, E. Isolauri, et al. Intestinal integrity and Akkermansia muciniphila: a mucin-degrading member of the intestinal microbiota present in infants, adults and the elderly. Appl Environ Microbiol 2007; 73 (22): 7767-7770 